Check for updates

Cite this: RSC Adv., 2020, 10, 30238

Received 26th June 2020

Accepted 6th August 2020

DOI: 10.1039/dOra05573e

rsc.li/rsc-advances

\title{
Dithiocarbamate-modified cellulose-based sorbents with high storage stability for selective removal of arsenite and hazardous heavy metals $\uparrow$
}

\author{
Futo Morita, $\ddagger^{a}$ Keisuke Nakakubo, (iD $\ddagger^{a}$ Koki Yunoshita, $\ddagger^{a}$ Masaru Endo, (D) ab \\ Foni B. Biswas, (D) ac Tatsuya Nishimura, (D) a Asami S. Mashio, (D) a \\ Hiroshi Hasegawa, (D) *a Tsuyoshi Taniguchi (D) *a and Katsuhiro Maeda (DD *ad
}

\begin{abstract}
A series of cellulose derivatives bearing dialkyl dithiocarbamate (DTC) groups were synthesized. Their ability of sorption of arsenite (As(III)) and heavy metals and their storage stability in the solid state were investigated. Among them, DTC-modified cellulose derived from L-proline showed the highest sorption capacity for As(III) and heavy metals to selectively remove them from aqueous media. It also showed exellent storage stability in air at $40{ }^{\circ} \mathrm{C}$.
\end{abstract}

\section{Introduction}

Compounds having a dithiocarbamate (DTC) group work as good chelating agents to capture heavy metals because the DTC group is a soft Lewis base that has strong affinity toward soft Lewis acids such as heavy metals to form stable complexes according to the HSAB rule. ${ }^{1,2}$ Several small organic molecules having a DTC group, such as sodium diethyldithiocarbamate, have been industrially used as sorbents for the removal of hazardous heavy metals from aqueous or organic media. ${ }^{3,4}$ Such small molecule-based sorbents are readily available, but further treatment is often required for the efficient removal of the resultant complexes from aqueous media due to the difficulty in precipitation of the heavy metal complexes. ${ }^{5}$ Polymer-based sorbents carrying a DTC group are potential materials for the removal of heavy metals from aqueous media because they can work as heterogeneous sorbents for solid-liquid extraction and can be easily recovered from water. ${ }^{6}$ However, typical polymerbased sorbents are synthesized from petroleum-based chemical materials, and the production of a large amount of waste acid solutions poses serious problem for the environment. ${ }^{7}$

Cellulose is the world's most abundant natural polymeric raw material with a fascinating structure and properties. ${ }^{8}$ This polysaccharide is capable of being chemically modified through

${ }^{a}$ Graduate School of Natural Science and Technology, Kanazawa University, Kakuma-machi, Kanazawa 920-1192, Japan. E-mail: hhiroshi@se.kanazawa-u.ac.jp; tsuyoshi@p.kanazawa-u.ac.jp; maeda@se.kanazawa-u.ac.jp

${ }^{b}$ Daicel Corporation, 1239 Shinzaike, Aboshi-ku, Himeji, Hyogo 671-1283, Japan 'Department of Chemistry, University of Chittagong, Chittagong 4331, Bangladesh ${ }^{d}$ Nano Life Science Institute (WPI-NanoLSI), Kanazawa University, Kakuma-machi, Kanazawa 920-1192, Japan

$\dagger$ Electronic supplementary information (ESI) available. See DOI: 10.1039/d0ra05573e

\$ These authors contributed equally. the hydroxyl groups in order to develop eco-friendly and costeffective biosorbents for wastewater treatment. Recently, our group synthesized a DTC-modified cellulose material 1 with excellent ability as a selective sorbent for highly toxic arsenite, which is an inorganic As(III) compound, from aqueous media (Fig. 1). ${ }^{9,10}$

It is generally believed that DTC compounds are stable in the solid state. During the course of the above study, however, we found that the sorption capacity of compound 1 for As(III) significantly decreased with time when it was stored even in the solid state under ambient conditions, probably due to decomposition of the DTC groups by moisture or oxygen. Although degradation behaviors of polymer-based sorbents having DTC groups in the solid state have not been investigated in detail, degradation might be a general problem for DTC-modified
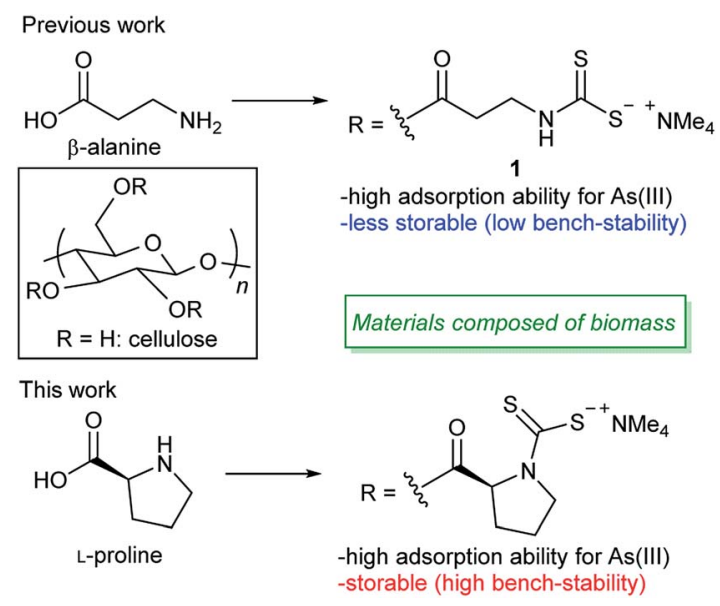

Fig. 1 DTC-modified cellulose-based sorbents for the selective removal of As(III). 


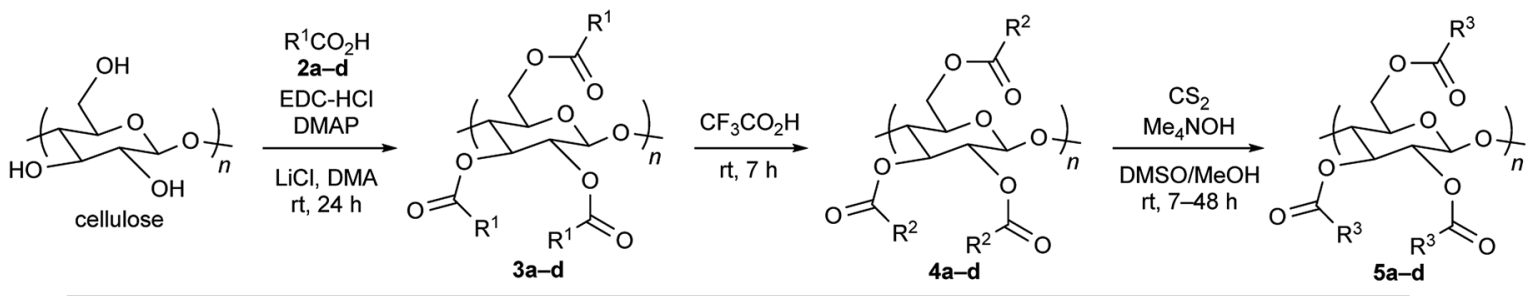

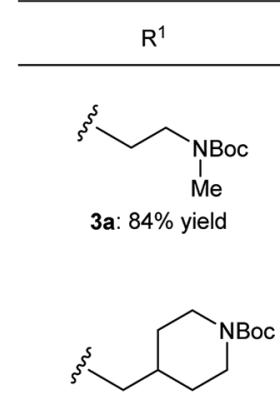

3b: $75 \%$ yield

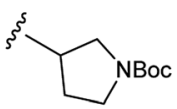

3c: $98 \%$ yield

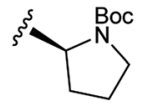

3d: $82 \%$ yield

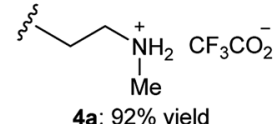<smiles>[Te]CC1CC[NH2+]CC1</smiles>

4b: $96 \%$ yield<smiles>CC1CC[NH2+]C1</smiles>

4c: $93 \%$ yield

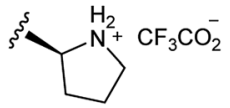

4d: $80 \%$ yield
$\mathrm{R}^{3}$

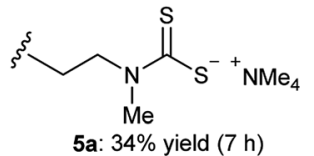

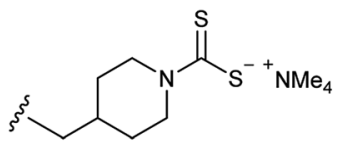

5b: $87 \%$ yield ( $48 \mathrm{~h}$ )<smiles>CC1CCN(C(=S)[S-][S+]C(C)C)C1</smiles>

5c: $83 \%$ yield $(48 \mathrm{~h})$<smiles>C[C@@H]1CCCN1C(=S)[Se-][Na]</smiles>

$5 d: 81 \%$ yield $(7 \mathrm{~h})$

Fig. 2 Synthesis of DTC-modified cellulose derivatives $5 a-d$.

polymer-based sorbents. This drawback would greatly limit the applicability of the material because manufacturing and transport of materials with poor storage stability are problematic.

We therefore decided to develop DTC-modified cellulose materials with good storage stability that are capable of efficiently removing toxic As(III) and heavy metals from aqueous media. Since monoalkyl DTC compounds $\left(\mathrm{R}-\mathrm{NH}-\mathrm{C}(=\mathrm{S}) \mathrm{S}^{-} ; \mathrm{R}=\right.$ alkyl group) have several competitive decomposition pathways based on the $\mathrm{N}-\mathrm{H}$ group,${ }^{11}$ they do not have sufficient stability

Table 1 Sorption capacity of 1 and $5 a-d$ for As(III)

\begin{tabular}{llll}
\hline & & \multicolumn{2}{l}{ Amounts of adsorbed As(III) $\left(\mu \mathrm{mol} \mathrm{g}^{-1}\right)^{a}$} \\
\cline { 3 - 4 } Entry & Sorbent & As is & After 2 weeks \\
\hline 1 & $\mathbf{1}$ & $595.3 \pm 5.1$ & $66.5 \pm 6.2(-89 \%)$ \\
2 & $\mathbf{5 a}$ & $480.6 \pm 20.9$ & $430.2 \pm 7.6(-11 \%)$ \\
3 & $\mathbf{5 b}$ & $332.1 \pm 2.6$ & $184.0 \pm 2.4(-45 \%)$ \\
4 & $\mathbf{5 c}$ & $489.5 \pm 40.9$ & $464.8 \pm 1.5(-5 \%)$ \\
5 & $\mathbf{5 d}$ & $618.8 \pm 17.6$ & $595.2 \pm 11.7(-4 \%)$
\end{tabular}

${ }^{a}$ Conditions: $[\mathrm{As}(\mathrm{III})]=2 \mathrm{mmol} \mathrm{L}{ }^{-1}$ at $\mathrm{pH} 3 .{ }^{b}$ Under air at $40{ }^{\circ} \mathrm{C}$. Percentage values in parentheses show a rate of decrease in the sorption capacity. compared with the stability of dialkyl DTC compounds. In this study, we synthesized a series of dialkyl DTC-modified $\left(-\mathrm{R}^{1}-\mathrm{N}\right.$ $\left(\mathrm{R}^{2}\right)-\mathrm{C}(=\mathrm{S}) \mathrm{S}^{-} ; \mathrm{R}^{1}$ and $\mathrm{R}^{2}=$ alkyl group) cellulose materials and evaluated their ability for sorption of As(III) and other heavy metals as well as their storage stability. As a result, we identified a novel biopolymer material derived from cellulose and $\mathrm{L}^{-}$ proline as a potential sorbent with excellent storage stability for selective sorption of As(III) and other heavy metals (Fig. 1).

\section{Results and discussion}

We began our study with the design and synthesis of four new DTC-modified cellulose compounds 5a-d (Fig. 2). First, commercially available microcrystalline cellulose was converted to the corresponding cellulose esters $\mathbf{3 a - d}$ by condensation between acyclic and cyclic $\mathrm{N}$-protected amino acid derivatives 2a-d in the presence of 1-ethyl-3-(3-dimethylaminopropyl) carbodiimide hydrochloride (EDC-HCl) and 4- $(N, N$-dimethylamino)pyridine (DMAP). Compounds $\mathbf{3 a - d}$ were readily soluble in organic solvents, and ${ }^{1} \mathrm{H}$ NMR and elemental analyses of 3a-d indicated that the degree of substitution (DS) was almost 3. Next, the tert-butoxycarbonyl group of 3a-d was removed by treatment with trifluoroacetic acid (TFA) to give secondary ammonium salts $\mathbf{4 a - d}$. Finally, treatment of $\mathbf{4 a - d}$ with $\mathrm{CS}_{2}$ and tetramethylammonium hydroxide provided the corresponding 


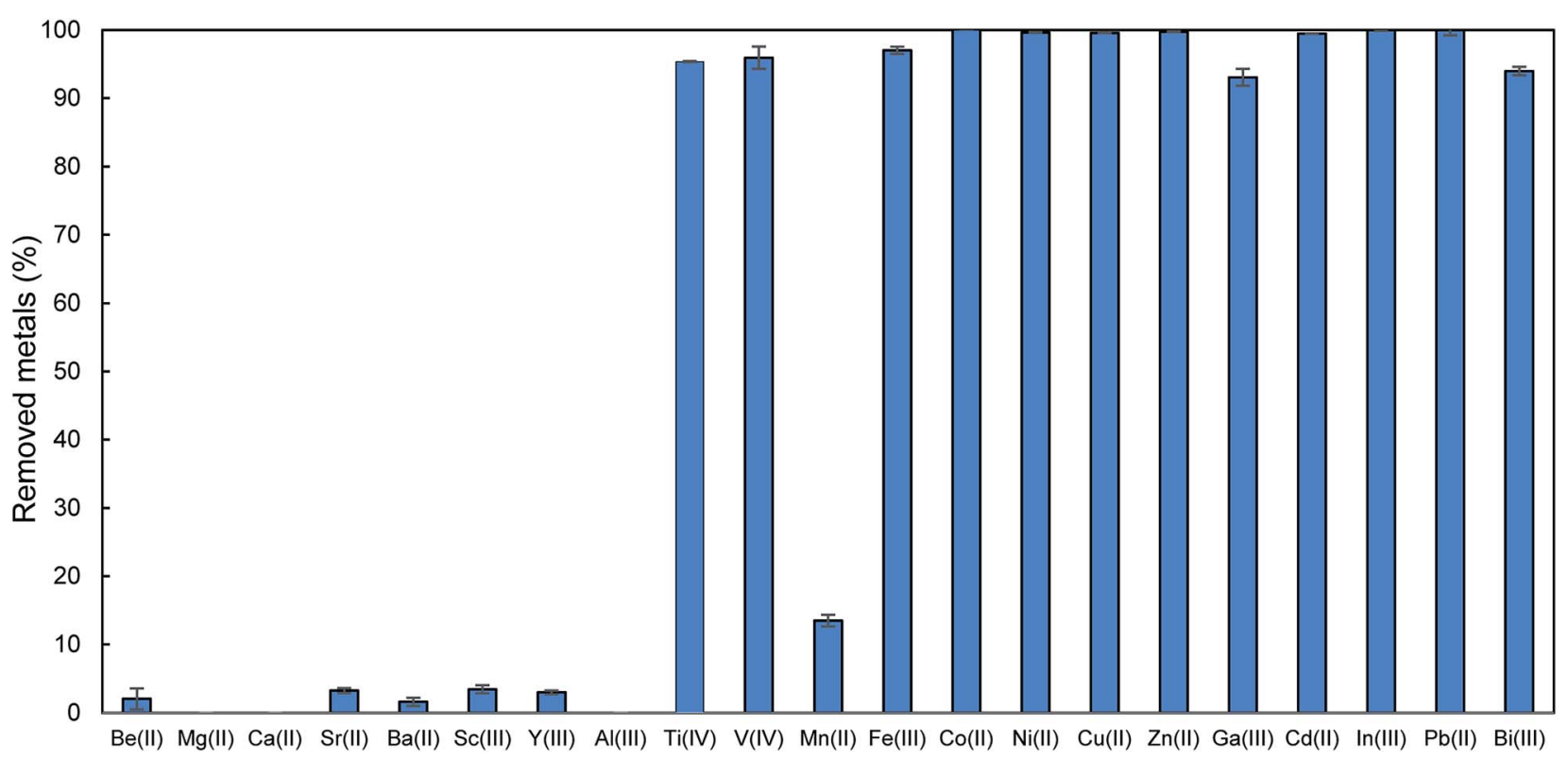

Fig. 3 Removal percentages of metals from $5 \mathrm{mg} \mathrm{L}^{-1}$ multi metal solution at $\mathrm{pH} 3$ using $5 \mathrm{~d}$.

dialkyl DTC-modified cellulose compounds $\mathbf{5 a - d}$ as white powders in good yields.§ Since compounds 5a-d were slightly soluble in water or acetic acid, ${ }^{1} \mathrm{H}$ NMR analysis of these compounds could be performed unlike in our previous study. ${ }^{9}$ Although ${ }^{1} \mathrm{H}$ NMR spectra of 5a-d showed rather broadened signals, they clearly indicated the existence of each side chain and tetramethylammonium cation (see ESI $\dagger$ ). IR spectra of $\mathbf{5 a}-$ d showed a typical and strong band at around $1730-1740 \mathrm{~cm}^{-1}$ based on $\mathrm{C}=\mathrm{O}$ stretching of ester groups. The spectra also displayed characteristic bands at around $1375-1485 \mathrm{~cm}^{-1}$ and 1155-1185 $\mathrm{cm}^{-1}$, which correspond to $\mathrm{N}-\mathrm{C}(\mathrm{S})$ and $\mathrm{C}=\mathrm{S}$ stretching of DTC groups, respectively. The $\mathrm{N}-\mathrm{C}(\mathrm{S})$ vibration characteristically shifted to a lower value in the order of acyclic 5a $\left(1485 \mathrm{~cm}^{-1}\right)>6$-membered cyclic $5 \mathbf{b}\left(1410 \mathrm{~cm}^{-1}\right)>5$ membered cyclic $5 \mathbf{c}\left(1384 \mathrm{~cm}^{-1}\right)$ and $\mathbf{5 d}\left(1375 \mathrm{~cm}^{-1}\right)$ (see ESI $\left.\dagger\right)$.

Next, we evaluated the sorption ability of the obtained dialkyl DTC-modified cellulose compounds 5a-d for As(III) (Table 1). Our previous study showed that the monoalkyl DTC-modified cellulose $\mathbf{1}$ had high capacity for sorption of As(III) in acidic and neutral conditions $(\leq \mathrm{pH} 7)$ because $\mathrm{As}(\mathrm{III})$ exists as a neutral form over a wide $\mathrm{pH}$ range $\left(\mathrm{p} K_{\mathrm{a} 1}=9.2\right),{ }^{9}$ and Ascontaining wastewater such as mining and smelting wastewater is usually acidic. ${ }^{12}$ Therefore, we tentatively compared the sorption capacities of compounds $\mathbf{5 a - d}$ for $\mathrm{As}(\mathrm{III})$ at $\mathrm{pH} 3$. Compound $\mathbf{5 a}$, which is an N-methylated analogue of $\mathbf{1}$, showed a lower sorption capacity than $\mathbf{1}$ (Table 1 , entries 1 and 2). The sorption capacity of compound $\mathbf{5 b}$ having a piperidine ring was also not good (Table 1, entry 3). Compound $\mathbf{5 c}$ having

$\S$ An appropriate caution (e.g., the use of safety glass and glove) should be paid for the use of potentially toxic reagents such as DMAP and $\mathrm{Me}_{4} \mathrm{NOH}$. In addition, the use of hazardous $\mathrm{CS}_{2}$ as a reagent is unavoidable for the synthesis of DTC compounds, but reacted $\mathrm{CS}_{2}$ is essentially incorporated to the material as a stable DTC group. a pyrrolidine ring showed better sorption capacity than $\mathbf{5 a}$ or $\mathbf{5 b}$, but its sorption capacity was still lower than that of $\mathbf{1}$ (Table 1 , entry 4). Finally, we found that the sorption capacity of compound 5d having a L-proline side chain is superior to that of 1 (Table 1, entry 5). The impact of reaction time in the introduction of DTC groups to 4d does not seem to be significant because $\mathbf{5 d}$ synthesized from $\mathbf{4 d}$ in a prolonged reaction time $(7 \mathrm{~h} \rightarrow 24 \mathrm{~h}$ ) did not show improved sorption capacity for $\operatorname{As}(\mathrm{III})\left(503.6 \pm 65.8 \mu \mathrm{mol} \mathrm{g}^{-1}\right)$.

We investigated the change in sorption capacity of compounds $\mathbf{1}$ and $\mathbf{5 a}-\mathbf{d}$ after they had been stored in air at $40{ }^{\circ} \mathrm{C}$ for 2 weeks (Table 1 ). The sorption capacity of compound 1 having an $\mathrm{N}-\mathrm{H}$ group was significantly decreased by about $89 \%$ after 2 weeks (Table 1, entry 1), and this was consistent with the gradual degradation observed in the course of storage under ambient conditions as mentioned in the introduction section. On the other hand, the sorption capacity of N-substituted DTC derivatives 5a-d did not decrease as much as that of compound 1 even after 2 weeks (Table 1, entries 2-5). Notably, the sorption capacity of $\mathbf{5 c}$ and $\mathbf{5 d}$ having a pyrrolidine moiety was hardly changed after 2 weeks (Table 1, entries 4 and 5), indicating that these sorbents are sufficiently stable to be stored for a long time under ambient conditions. $\uparrow$ Consequently, 5d having a Lproline side chain was identified as a practical DTC-modified cellulose-based sorbent with both high sorption capacity and excellent storage stability. These good properties of $\mathbf{5 d}$ might be due to the high nucleophilicity of a pyrrolidine moiety, which could strongly ligate $\mathrm{CS}_{2} \cdot{ }^{13,14}$ However, it is unclear why the sorption capacity of $\mathbf{5 d}$ is different.

Finally, we preliminary tested the efficiency of compound $\mathbf{5 d}$ for the removal of other metal ions using aqueous solutions

I After exposing the materials to air at $40{ }^{\circ} \mathrm{C}$ for 2 weeks, the IR spectrum of $\mathbf{1}$ greatly changed whereas those of $\mathbf{5 d}$ hardly changed (Fig. S1 and S2 $\dagger$ ). 
containing 21 representative metal ions together with As(III) as shown in Fig. 3. Compound 5d adsorbed heavy metals, including V(IV), $\mathrm{Fe}(\mathrm{III}), \mathrm{Co}(\mathrm{II}), \mathrm{Ni}(\mathrm{II}), \mathrm{Cu}(\mathrm{II}), \mathrm{Zn}$ (II), Ga(III), Cd(II), In(III), $\mathrm{Pb}$ (II) and $\mathrm{Bi}(\mathrm{III})$, with high efficiency. ${ }^{\mathbf{1} 9}$ In contrast, compound 5d hardly adsorbed alkaline earth metal ions, which are hard metals. This trend is very similar to that of $\mathbf{1}$ and is consistent with the HSAB rule. ${ }^{2}$ Exceptionally, Ti(Iv), which is a hard acid, was efficiently adsorbed by $\mathbf{5 d}$, and this might be because $\mathrm{Ti}(\mathrm{Iv})$ could form a stable multidentate complex with DTC groups like other heavy metals. ${ }^{15}$ Thus, $\mathbf{5 d}$ is a potential sorbent for the selective and efficient removal of As(III) and other hazardous heavy metals from natural water or wastewater with high concentrations of hard metal ions such as alkaline earth metal ions.

\section{Conclusions}

We have developed a new dialkyl DTC-modified biomass-based sorbent $\mathbf{5 d}$ derived from cellulose and L-proline. This sorbent is a potential material for the selective removal of toxic As(III) and other heavy metals from aqueous media because it has high capacity for As(III) and other hazardous heavy metals but hardly adsorbs alkaline earth metal ions. The sorption capacity and stability was maintained even after exposure to air at $40{ }^{\circ} \mathrm{C}$ for 2 weeks, indicating its excellent storage stability for practical use. In contrast, a significant decrease in the sorption capacity for As(III) was observed for monoalkyl DTC-modified compound 1, suggesting that monoalkyl DTC-modified polymer-based sorbents might have poor storage ability, and caution is therefore required for the practical use of such materials. The present study demonstrated development of an improved sorbent for the selective removal of As(III) and other heavy metals based on a solid molecular design with biopolymer. Studies for further improvement and practical applications of the material are ongoing in our laboratory.

\section{Experimental}

\section{General remarks}

1.1. For synthetic experiments. All reactions were performed in oven-dried glassware. All reagents purchased commercially were used without further purification unless otherwise noted. Dehydrated solvents were purchased from Kanto Chemical Co., Inc. Cellulose (Avicel, DP: ca. 200) was purchased from Merck. $N$-(tert-Butoxycarbonyl)- $N$-Me- $\beta$-alanine (2a) was prepared by methylation of commercially available $N$ (tert-butoxycarbonyl)- $\beta$-alanine with iodomethane. ${ }^{16}$-(1-(tertButoxycarbonyl)piperidin-4-yl)acetic acid (2b), 1-(tertbutoxycarbonyl)pyrrolidine-3-carboxylic acid (2c), (tert-butoxycarbonyl)-L-proline (2d) and tetramethylammonium hydroxide $\left(\mathrm{Me}_{4} \mathrm{NOH}, 10 \%\right.$ in methanol) were purchased from Tokyo Chemical Industry Co., Ltd. (TCI). Lithium chloride, 1-ethyl-3(3-dimethylaminopropyl)carbodiimide hydrochloride (EDC$\mathrm{HCl}$ ), $N, N$-dimethyl-4-aminopyridine (DMAP), trifluoroacetic acid (TFA), and carbon disulfide were purchased from Wako Pure Chemical. DTC-modified cellulose $\mathbf{1}$ was prepared according to the procedure previously reported. ${ }^{9}$
${ }^{1} \mathrm{H}$ NMR spectra were recorded on Bruker Avance 400 and JEOL JNM-ECA 500 spectrometers at $20{ }^{\circ} \mathrm{C}$ unless otherwise noted. Chemical shifts $(\delta)$ are quoted relative to tetramethylsilane $\left({ }^{1} \mathrm{H} \mathrm{NMR}, \delta 0 \mathrm{ppm}\right)$ or a solvent residual peak $\left(\mathrm{D}_{2} \mathrm{O}\right.$ : $\left.\delta 4.79 \mathrm{ppm} ; \mathrm{CD}_{3} \mathrm{CO}_{2} \mathrm{D}: \delta 2.04 \mathrm{ppm}\right)$ as the internal standard. Coupling constants $(J)$ are given in Hz. Multiplicities are indicated as follows: s (singlet), d (doublet), t (triplet), q (quartet), $\mathrm{m}$ (multiplet), or br (broadened). IR spectra were recorded with a JASCO Fourier Transform IR-4700 spectrophotometer. Elemental analyses were performed by the Research Institute for Instrumental Analysis of Advanced Science Research Center, Kanazawa University or by the Research Initiative Center, Tottori University.

1.2. For batch sorption experiments. All laboratory wares were soaked in an alkaline detergent (Scat 20X-PF; Nacalai Tesque) overnight, and then rinsed with deionized water. Subsequently, they were soaked in $3 \mathrm{~mol} \mathrm{~L}^{-1} \mathrm{HCl}$ overnight, and then washed again with deionized water. As(III) standard solution (1000 $\left.\mathrm{mg} \mathrm{L}^{-1}\right)$, sodium hydroxide $(\mathrm{NaOH})$, nitric acid $\left(\mathrm{HNO}_{3}, 60 \%\right)$ and acetic acid $(\mathrm{AcOH}, 99 \%)$ were purchased from Kanto Chemical. Sodium acetate (AcONa) was purchased from Nacalai Tesque. ICP multi-element standard solution IV containing 21 elements (Al, Ba, Be, Bi, Ca, Cd, Co, Cu, Fe, Ga, In, K, $\mathrm{Li}, \mathrm{Mg}, \mathrm{Mn}, \mathrm{Na}, \mathrm{Ni}, \mathrm{Pb}, \mathrm{Sr}, \mathrm{Y}, \mathrm{Zn}$ ) was purchased from GL science.

The metal concentrations were quantified with inductively coupled plasma optical emission spectrometry (ICP-OES; iCAP 6300; Thermo Fisher Scientific). For $\mathrm{pH}$ measurements, a $\mathrm{pH}$ meter (Navi F-52; Horiba Instruments) was used. In order to prepare deionized water with a resistivity of $>18.2 \mathrm{M} \Omega \mathrm{cm}$, an Arium Pro water purification system (Sartorius Stedium Biotech $\mathrm{GmbH}$ ) was used. A natural incubator (NIB-82; Iwaki Asahi Techno Glass) was used for heating.

\section{Experimental details}

\subsection{Synthetic experiments}

2.1.1. Synthesis of $\mathbf{3 a - d}$ (esterification). After cellulose (1 equiv.) was dried for $2 \mathrm{~h}$ at $90{ }^{\circ} \mathrm{C}$ in vacuo $(0.1 \mathrm{mmHg})$, DMA $\left(5.4 \mathrm{~mL} \mathrm{mmol}^{-1}\right)$ was added, and the resultant slurry was stirred for $20 \mathrm{~h}$ at $90{ }^{\circ} \mathrm{C}$. $\mathrm{LiCl}$ ( $\mathrm{ca} .7-8$ equiv.) was added to the slurry precooled to room temperature, and the mixture was stirred for $1 \mathrm{~h}$ at room temperature. 2a-d (6 equiv.), DMAP (6 equiv.) and EDC-HCl ( 6 equiv.) were added to the resultant solution at $0{ }^{\circ} \mathrm{C}$, and the mixture was stirred for $24 \mathrm{~h}$ at room temperature. The reaction mixture was poured into an excess amount of $\mathrm{MeOH} /$ $\mathrm{H}_{2} \mathrm{O}(70 / 30-80 / 20, \mathrm{v} / \mathrm{v})$ under stirring. The formed precipitate was collected by centrifugation, washed with $\mathrm{MeOH} / \mathrm{H}_{2} \mathrm{O}(80 / 20$, $\mathrm{v} / \mathrm{v}$ ), and dried in vacuo to give 3a-d. The product was often contaminated with small amounts of waste based on reagents used in the reaction, but those could be used for the next step without further purification. For identification, the purer product could be obtained by repeating precipitation and washing with $\mathrm{MeOH} / \mathrm{H}_{2} \mathrm{O}$.

3a. Cellulose (301 mg, $1.86 \mathrm{mmol})$, DMA (20 mL), LiCl (642 mg, $15.1 \mathrm{mmol}), 2 \mathrm{a}$ (2.29 g, $11.3 \mathrm{mmol}), \operatorname{DMAP}(1.38 \mathrm{~g}, 11.3$ $\mathrm{mmol})$ and EDC-HCl $(2.16 \mathrm{~g}, 11.3 \mathrm{mmol})$ were used for the 
reaction to give $3 \mathrm{a}(1.17 \mathrm{~g}, 84 \%$ yield $)$ as a white solid. ${ }^{1} \mathrm{H}$ NMR $\left(500 \mathrm{MHz}, \mathrm{CDCl}_{3}, 55^{\circ} \mathrm{C}\right): \delta 5.05(\mathrm{br}, 1 \mathrm{H}), 4.73(\mathrm{br}, 1 \mathrm{H}), 4.55(\mathrm{br}$, $1 \mathrm{H}), 4.48$ (br, 1H), 4.07 (br, 1H), 3.33-3.70 (m, 8H), 2.82-2.87 (m, 9H), 2.43-2.56 (m, 6H), 1.43 (s, 27H); IR (KBr, $\left.\mathrm{cm}^{-1}\right): 1745,1691$. Anal. calcd for $\mathrm{C}_{33} \mathrm{H}_{55} \mathrm{~N}_{3} \mathrm{O}_{14} \cdot \mathrm{H}_{2} \mathrm{O}$ : C, 53.87; H, 7.81; N, 5.71. Found: C, 54.12; H, 7.58; N, 5.70.

3b. Cellulose (1.00 g, $6.17 \mathrm{mmol})$, DMA (31 mL), LiCl (1.96 g, $46.3 \mathrm{mmol}$ ), $2 \mathrm{~b}$ (9.00 g, $37.0 \mathrm{mmol}$ ), DMAP (4.52 g, $37.0 \mathrm{mmol}$ ) and $\mathrm{EDC}-\mathrm{HCl}(7.09 \mathrm{~g}, 37.0 \mathrm{mmol})$ were used for the reaction to give $3 \mathbf{b}\left(3.87 \mathrm{~g}, 75 \%\right.$ yield) as a white solid. ${ }^{1} \mathrm{H}$ NMR $(500 \mathrm{MHz}$, $\left.\mathrm{CDCl}_{3}, 55{ }^{\circ} \mathrm{C}\right): \delta 5.06$ (br, $\left.1 \mathrm{H}\right), 4.68(\mathrm{br}, 1 \mathrm{H}), 4.53(\mathrm{br}, 1 \mathrm{H}), 4.34$ (br, 1H), 3.93-4.20 (m, 7H), 3.76 (br, 1H), 3.51 (br, 1H), $2.72(\mathrm{br}$, 6H), 2.10-2.30 (m, 6H), 1.55-1.95 (br, 9H), 1.45 (s, 27H), 1.00$1.25(\mathrm{~m}, 6 \mathrm{H})$; IR $\left(\mathrm{KBr}, \mathrm{cm}^{-1}\right)$ : 1747, 1691. Anal. calcd for $\mathrm{C}_{42} \mathrm{H}_{67} \mathrm{~N}_{3} \mathrm{O}_{14}: \mathrm{C}, 60.20 ; \mathrm{H}, 8.06 ; \mathrm{N}, 5.01$. Found: C, 59.81; H, 8.22; N, 5.04 .

3c. Cellulose (253 mg, $1.56 \mathrm{mmol})$, DMA (9.4 mL), LiCl (528 mg, $12.5 \mathrm{mmol}$ ), $2 \mathrm{c}$ (2.03 g, $9.43 \mathrm{mmol}$ ), DMAP (1.17 g, 9.56 $\mathrm{mmol})$ and EDC-HCl $(1.79 \mathrm{~g}, 9.35 \mathrm{mmol})$ were used for the reaction to give $3 \mathrm{c}\left(1.15 \mathrm{~g}, 98 \%\right.$ yield) as a white solid. ${ }^{1} \mathrm{H}$ NMR $\left(500 \mathrm{MHz}, \mathrm{CDCl}_{3}, 55^{\circ} \mathrm{C}\right): \delta 5.07(\mathrm{br}, 1 \mathrm{H}), 4.00-4.72(\mathrm{~m}, 3 \mathrm{H})$, 2.70-3.90 (m, 18H), 1.90-2.30 (m, 6H), 1.45 (s, 27H); IR $\left(\mathrm{KBr}, \mathrm{cm}^{-1}\right): 1751,1691$. Anal. calcd for $\mathrm{C}_{36} \mathrm{H}_{55} \mathrm{~N}_{3} \mathrm{O}_{14} \cdot 0.5 \mathrm{H}_{2} \mathrm{O}: \mathrm{C}$, 56.68; H, 7.40; N, 5.51. Found: C, 56.68; H, 7.33; N, 5.55.

3d. Cellulose (1.25 g, $7.71 \mathrm{mmol})$, DMA (42 mL), LiCl (2.60 g, $61.4 \mathrm{mmol}), 2 \mathrm{~d}$ (10.0 g, $46.6 \mathrm{mmol})$, DMAP (5.72 g, $46.8 \mathrm{mmol})$ and EDC-HCl ( $9.00 \mathrm{~g}, 47.0 \mathrm{mmol})$ were used for the reaction to give $3 \mathrm{~d}$ (4.82 g, 82\% yield) as a white solid. ${ }^{1} \mathrm{H}$ NMR (500 MHz, $\mathrm{CDCl}_{3}, 55{ }^{\circ} \mathrm{C}$ ): $\delta 3.20-5.20$ (br, $\left.16 \mathrm{H}\right), 1.58-2.40$ (br, $\left.12 \mathrm{H}\right), 1.43$ (br, 27H); IR (KBr, cm ${ }^{-1}$ ): 1755,1709 . Anal. calcd for $\mathrm{C}_{36} \mathrm{H}_{55^{-}}$ $\mathrm{N}_{3} \mathrm{O}_{14} \cdot \mathrm{H}_{2} \mathrm{O}$ : C, 56.02; H, 7.44; N, 5.44. Found: C, 55.92; H, $7.31 ; \mathrm{N}, 5.45$.

2.1.2. Synthesis of $\mathbf{4 a - d}$ (deprotection). TFA ( $5 \mathrm{~mL} \mathrm{mmol}{ }^{-1}$ ) was added to $\mathbf{3 a - d}$, and the mixture was stirred for $7 \mathrm{~h}$ at room temperature. The reaction mixture was poured into an excess amount of $\mathrm{Et}_{2} \mathrm{O}$ under stirring. The formed precipitate was collected by centrifugation, washed with $\mathrm{Et}_{2} \mathrm{O}$, and dried in vacuo to give $\mathbf{4 a - d}$.

4a. TFA (7.8 $\mathrm{mL})$ and $3 \mathrm{a}(1.17 \mathrm{~g}, 1.63 \mathrm{mmol})$ were used for the reaction to give $4 \mathrm{a}(1.08 \mathrm{~g}, 92 \%$ yield $)$ as a white solid. ${ }^{1} \mathrm{H}$ NMR $\left(500 \mathrm{MHz}, \mathrm{D}_{2} \mathrm{O}, 80{ }^{\circ} \mathrm{C}\right): \delta 5.71(\mathrm{br}, 1 \mathrm{H}), 4.10-5.40(\mathrm{~m}, 6 \mathrm{H}$, partially overlapped with a water signal), 3.85 (br, $6 \mathrm{H}), 3.20-3.55$ ( $\mathrm{m}, 15 \mathrm{H}$ ), the signal based on $\mathrm{NH}_{2}$ was not observed due to $\mathrm{H}-\mathrm{D}$ exchange; IR ( $\mathrm{KBr}, \mathrm{cm}^{-1}$ ): 1750, 1681. Anal. calcd for $\mathrm{C}_{24} \mathrm{H}_{34^{-}}$ $\mathrm{N}_{3} \mathrm{O}_{14} \mathrm{~F}_{9} \cdot 2 \mathrm{H}_{2} \mathrm{O}: \mathrm{C}, 36.23 ; \mathrm{H}, 4.81 ; \mathrm{N}, 5.28$. Found: C, 36.32; $\mathrm{H}$, $4.43 ; \mathrm{N}, 5.22$.

4b. TFA ( $8.0 \mathrm{~mL})$ and $3 \mathbf{b}(1.36 \mathrm{~g}, 1.62 \mathrm{mmol})$ were used for the reaction to give $\mathbf{4 b}(1.37 \mathrm{~g}, 96 \%$ yield $)$ as a white solid. ${ }^{1} \mathrm{H}$ NMR $\left(500 \mathrm{MHz}, \mathrm{D}_{2} \mathrm{O}\right): \delta 5.09(\mathrm{br}, 1 \mathrm{H}), 4.30-4.80(\mathrm{~m}, 5 \mathrm{H}$, partially overlapped with a water signal), 3.75 (br, $1 \mathrm{H}), 3.42$ (br, 6H), 2.98 (br, 6H), 1.80-2.50 (m, 15H), 1.30-1.50 (m, 6H), the signal based on $\mathrm{NH}_{2}$ was not observed due to $\mathrm{H}-\mathrm{D}$ exchange; IR $\left(\mathrm{KBr}, \mathrm{cm}^{-1}\right)$ : 1745, 1689. Anal. calcd for $\mathrm{C}_{33} \mathrm{H}_{46} \mathrm{~N}_{3} \mathrm{O}_{14} \mathrm{~F}_{9} \cdot 2 \mathrm{H}_{2} \mathrm{O}: \mathrm{C}, 43.28 ; \mathrm{H}$, 5.50; N, 4.59. Found: C, 42.84; H, 5.07; N, 4.51. 4c. TFA (32 mL) and $3 c(4.80 \mathrm{~g}, 6.37 \mathrm{mmol})$ were used for the reaction to give $4 \mathrm{c}(4.73 \mathrm{~g}, 93 \%$ yield $)$ as a white solid. ${ }^{1} \mathrm{H}$ NMR $\left(500 \mathrm{MHz}, \mathrm{D}_{2} \mathrm{O}\right): \delta 5.19(\mathrm{br}, 1 \mathrm{H}), 3.303 .80-4.80(\mathrm{~m}, 6 \mathrm{H}$, partially overlapped with a water signal), 3.30-3.70 (m, 12H), 1.70-2.50 $(\mathrm{m}, 9 \mathrm{H})$, the signal based on $\mathrm{NH}_{2}$ was not observed due to $\mathrm{H}-\mathrm{D}$ exchange; IR ( $\left.\mathrm{KBr}, \mathrm{cm}^{-1}\right): 1747,1679$. Anal. calcd for $\mathrm{C}_{27} \mathrm{H}_{34^{-}}$ $\mathrm{N}_{3} \mathrm{O}_{14} \mathrm{~F}_{9} \cdot \mathrm{H}_{2} \mathrm{O}$ : C, 39.86; H, 4.46; N, 5.16. Found: C, 39.49; H, 4.28 ; N, 5.15 .

4d. TFA (32 mL) and 3d (4.82 g, $6.40 \mathrm{mmol})$ were used for the reaction to give $4 \mathbf{d}\left(4.09 \mathrm{~g}, 80 \%\right.$ yield) as a white solid. ${ }^{1} \mathrm{H}$ NMR $\left(500 \mathrm{MHz}, \mathrm{D}_{2} \mathrm{O}\right): \delta 5.42(\mathrm{br}, 1 \mathrm{H}), 4.55-5.20(\mathrm{~m}, 5 \mathrm{H}$, partially overlapped with a water signal), 3.80-4.40 (m, $4 \mathrm{H}), 3.50$ (br, $6 \mathrm{H})$, 1.85-2.70 (m, 12H), the signal based on $\mathrm{NH}_{2}$ was not observed due to $\mathrm{H}$-D exchange; IR $\left(\mathrm{KBr}, \mathrm{cm}^{-1}\right): 1755,1678$. Anal. calcd for $\mathrm{C}_{27} \mathrm{H}_{34} \mathrm{~N}_{3} \mathrm{O}_{14} \mathrm{~F}_{9} \cdot \mathrm{H}_{2} \mathrm{O}$ : C, 39.86; H, 4.46; N, 5.16. Found: C, 39.55; $\mathrm{H}, 4.54 ; \mathrm{N}, 4.97$.

2.1.3. Synthesis of $\mathbf{5 a - d}$ (dithiocarbamation). To a solution of 4a-d in DMSO ( $5 \mathrm{~mL} \mathrm{mmol}^{-1}$ ) was added $\mathrm{CS}_{2}$ (15 equiv.) and $10 \% \mathrm{Me}_{4} \mathrm{NOH}$ solution in $\mathrm{MeOH}$ (ca. 6-7 equiv.) at $0{ }^{\circ} \mathrm{C}$, and the resultant suspension was stirred at room temperature. The reaction mixture became almost homogeneous in 7-48 h. The reaction mixture was poured into an excess amount of $\mathrm{MeOH}$ (for $\mathbf{4 a}$ and $\mathbf{4 b}$ ) or EtOH (for $\mathbf{4 c}$ and $\mathbf{4 d}$ ) under stirring. The formed precipitate was collected by centrifugation, washed with $\mathrm{MeOH}$ (for $\mathbf{4 a}$ and $\mathbf{4 b}$ ) or EtOH (for $\mathbf{4 c}$ and $\mathbf{4 d}$ ), and dried in vacuo to give $\mathbf{5 a - d}$.

5a. $4 \mathrm{a}(1.55 \mathrm{~g}, 2.04 \mathrm{mmol}), \mathrm{DMSO}(10 \mathrm{~mL}), \mathrm{CS}_{2}(1.84 \mathrm{~mL}, 30.5$ $\mathrm{mmol}$ ) and $10 \% \mathrm{Me}_{4} \mathrm{NOH}$ solution in $\mathrm{MeOH}(14 \mathrm{~mL}, 13.9$ $\mathrm{mmol}$ ) were used for the reaction $(7 \mathrm{~h})$ to give $5 \mathrm{a}(605 \mathrm{mg}, 34 \%$ yield) as a white solid. ${ }^{1} \mathrm{H}$ NMR (500 MHz, $\left.\mathrm{D}_{2} \mathrm{O}\right): \delta 3.90-5.50(\mathrm{~m}$, $7 \mathrm{H}$, partially overlapped with a water signal), 3.45 (br, $6 \mathrm{H}), 3.18$ (br, 9H), 3.16 (s, 36H); IR (KBr, $\mathrm{cm}^{-1}$ ): 1741, 1485, 1156. The value observed by elemental analysis was significantly different from the theoretical value because the sample contained a significant amount of water or because the side chain was partially degraded by hydrolysis (for example, Anal. calcd for $\mathrm{C}_{33} \mathrm{H}_{64} \mathrm{~N}_{6} \mathrm{O}_{8} \mathrm{~S}_{6}$ : C, 45.81; H, 7.46; N, 9.71. Found: C, 41.42; $\mathrm{H}$, $7.13 ; \mathrm{N}, 8.14)$.

5b. 4b (507 mg, $0.576 \mathrm{mmol})$, DMSO (2.8 mL), $\mathrm{CS}_{2}(0.52 \mathrm{~mL}$, $8.61 \mathrm{mmol}$ ) and $10 \% \mathrm{Me}_{4} \mathrm{NOH}$ solution in $\mathrm{MeOH}(3.7 \mathrm{~mL}, 3.66$ $\mathrm{mmol}$ ) were used for the reaction $(48 \mathrm{~h})$ to give $\mathbf{5 b}(496 \mathrm{mg}, 87 \%$ yield) as a white solid. ${ }^{1} \mathrm{H}$ NMR (500 $\left.\mathrm{MHz}, \mathrm{CD}_{3} \mathrm{CO}_{2} \mathrm{D}\right): \delta 3.70-$ $5.50(\mathrm{~m}, 7 \mathrm{H}), 3.54$ (br, 6H), 3.22 (s, 36H), 3.09 (br, 6H), 1.80-2.50 (br, $15 \mathrm{H}$, partially overlapped with a solvent signal), 1.40-1.70 (m, 6H); IR ( $\left.\mathrm{KBr}, \mathrm{cm}^{-1}\right): 1741,1410,1174$. The value observed by elemental analysis was significantly different from the theoretical value because the sample contained a significant amount of water or because the side chain was partially degraded by hydrolysis (for example, Anal. calcd for $\mathrm{C}_{42} \mathrm{H}_{76} \mathrm{~N}_{6} \mathrm{O}_{8} \mathrm{~S}_{6}$ : C, 51.19; H, 7.77; N, 8.53. Found: C, 47.76; H, 6.69; N, 6.43).

5c. $4 c$ (421 mg, $0.529 \mathrm{mmol})$, DMSO (2.7 mL), $\mathrm{CS}_{2}(0.49 \mathrm{~mL}$, $8.12 \mathrm{mmol}$ ) and $10 \% \mathrm{Me}_{4} \mathrm{NOH}$ solution in $\mathrm{MeOH}(3.7 \mathrm{~mL}, 3.66$ $\mathrm{mmol}$ ) were used for the reaction (48 h) to give $5 \mathrm{c}(404 \mathrm{mg}, 83 \%$ yield) as a white solid. ${ }^{1} \mathrm{H}$ NMR (500 MHz, $\left.\mathrm{D}_{2} \mathrm{O}\right): \delta 5.27(\mathrm{br}, 1 \mathrm{H})$, 
$3.30-5.00(\mathrm{~m}, 18 \mathrm{H}$, partially overlapped with a water signal), 3.20 (s, 36H), 1.90-2.70 (br, 9H).; IR ( $\mathrm{KBr}, \mathrm{cm}^{-1}$ ): 1740, 1384, 1165. The value observed by elemental analysis was significantly different from the theoretical value because the sample contained a significant amount of water or because the side chain was partially degraded by hydrolysis (for example, Anal. calcd for $\mathrm{C}_{36} \mathrm{H}_{64} \mathrm{~N}_{6} \mathrm{O}_{8} \mathrm{~S}_{6}: \mathrm{C}, 47.97 ; \mathrm{H}, 7.15 ; \mathrm{N}, 9.32$. Found: $\mathrm{C}, 44.32 ; \mathrm{H}$, $7.34 ; \mathrm{N}, 8.51)$.

5d. 7 h: $4 d$ (1.00 g, $1.26 \mathrm{mmol})$, DMSO (6.3 mL), CS 2 (1.14 mL, $18.9 \mathrm{mmol})$ and $10 \% \mathrm{Me}_{4} \mathrm{NOH}$ solution in $\mathrm{MeOH}(8.7 \mathrm{~mL}, 8.61$ $\mathrm{mmol}$ ) were used for the reaction ( $7 \mathrm{~h}$ ) to give $5 \mathrm{~d}$ (915 $\mathrm{mg}, 81 \%$ yield) as a white solid. $24 \mathrm{~h}$ : $4 d$ (504 mg, $0.633 \mathrm{mmol})$, DMSO (3.1 mL), $\mathrm{CS}_{2}(0.57 \mathrm{~mL}, 9.44 \mathrm{mmol})$ and $10 \% \mathrm{Me}_{4} \mathrm{NOH}$ solution in $\mathrm{MeOH}$ (4.3 mL, $4.27 \mathrm{mmol}$ ) were used for the reaction $(24 \mathrm{~h})$ to give 5d (519 mg, 91\% yield) as a white solid. ${ }^{1} \mathrm{H}$ NMR (500 $\left.\mathrm{MHz}, \mathrm{D}_{2} \mathrm{O}\right): \delta 5.04(\mathrm{br}, 3 \mathrm{H}$, partially overlapped with a water signal), 3.90 (br, 6H), 3.17 (s, 36H), 1.70-2.60 (br, 12H), signals based on the cellulose moiety $(7 \mathrm{H})$ were obscure due to broadening; IR (KBr, $\left.\mathrm{cm}^{-1}\right)$ : 1737, 1375, 1183. The value observed by elemental analysis was significantly different from the theoretical value because the sample contained a significant amount of water or because the side chain was partially degraded by hydrolysis (for example, Anal. calcd for $\mathrm{C}_{36} \mathrm{H}_{64} \mathrm{~N}_{6} \mathrm{O}_{8} \mathrm{~S}_{6}$ : C, 47.97; H, 7.15; N, 9.32. Found: C, 42.50; H, 7.40; N, 7.81).

2.2. Batch sorption experiments. The durability of the sorbents was investigated by comparing the sorption capacities of As(III) before and after keeping them at $40{ }^{\circ} \mathrm{C}$ for fortnight. Sorption tests were conducted in $50 \mathrm{~mL}$ centrifuge tubes containing $0.02 \mathrm{~g}$ of sorbent and $10 \mathrm{~mL}$ of $2 \mathrm{mmol} \mathrm{L}^{-1} \mathrm{As}$ (III) solutions by agitating the tubes for 20 minutes at $25{ }^{\circ} \mathrm{C}$ and $200 \mathrm{rpm}$. Then, the solutions were collected by filtrating suspensions through a $0.45 \mu \mathrm{m}$ membrane filter. Subsequently, the metal concentrations in the solutions were determined with ICP-OES. The sorption capacities of As(III) $\left(q_{\mathrm{e}}\right)$ were calculated according to the equation shown below:

$$
q_{\mathrm{e}}=\frac{\left(C_{\mathrm{i}}-C_{\mathrm{e}}\right)}{m} V
$$

where $q_{\mathrm{e}}\left(\mu \mathrm{mol} \mathrm{g}{ }^{-1}\right)$ represents the sorption capacity of As(III), $C_{\mathrm{i}}$ and $C_{\mathrm{e}}\left(\mu \mathrm{mol} \mathrm{\textrm {L } ^ { - 1 }}\right)$ refer to initial and equilibrium concentrations of $\mathrm{As}(\mathrm{III}), m(\mathrm{~g})$ is the weight of the sorbent, and $V(\mathrm{~L})$ is the solution volume.

The removal efficiency of various elements was examined using polymer 5d. The solution containing 21 elements was prepared by diluting the desired amount of the ICP multielement standard solution with deionized water so that the concentrations became $5 \mathrm{mg} \mathrm{L}^{-1}$. Then, the $\mathrm{pH}$ was adjusted to pH 3 using $0.1 \mathrm{~mol} \mathrm{~L}^{-1} \mathrm{HNO}_{3}$ or $\mathrm{NaOH}$ solution, and sorption tests were carried out according to the procedure mentioned above. The removed metal percentages (\%) were calculated from the following equation:

$$
\text { Removed metal }(\%)=\frac{\left(C_{\mathrm{i}}-C_{\mathrm{e}}\right)}{C_{i}} \times 100
$$

\section{Conflicts of interest}

The authors declare the following conflict of interest(s): Kanazawa University and Daicel Corporation hold or have a filed patent related to this work (Patent Application No. PCT/JP2020/ 21903).

\section{Acknowledgements}

This work was financially supported by Daicel Corporation and JSPS KAKENHI (Grant-in-Aid for Scientific Research (C), No. 18K04723).

\section{Notes and references}

1 S. Kanchi, P. Singh and K. Bisetty, Arabian J. Chem., 2014, 7, 11.

2 R. G. Pearson, J. Am. Chem. Soc., 1963, 85, 3533.

3 R. E. Wing and W. E. Rayford, Plat. Surf. Finish., 1982, 69, 67. 4 W. P. Gallagher and A. Vo, Org. Process Res. Dev., 2015, 19, 1369.

5 For instance, the use of coprecipitating reagents or anionexchange resins are known: $(a)$ G. T. Shen and E. A. Boyle, Chem. Geol., 1988, 67, 47; (b) K. Anezaki, I. Nukatsuka and K. Ohzeki, Anal. Sci., 1999, 15, 829.

6 Recent examples of polymer-bound DTC materials: (a) Q. Li, J. Yu, F. Zhou and X. Jiang, Colloids Surf., A, 2015, 482, 306; (b) B. Xiang, W. Fan, X. Yi, Z. Wang, F. Gao, Y. Li and H. Gu, Carbohydr. Polym., 2016, 136, 30; (c) X. Shi, L. Fu, Y. Wu, H. Zhao, S. Zhao and S. Xu, Appl. Water Sci., 2017, 7, 4351; (d) O. C. S. Al Hamouz, M. Estatie and T. A. Saleh, Sep. Purif. Technol., 2017, 177, 101; (e) M. Behjati, M. Baghdadi and A. Karbassi, J. Environ. Manage., 2018, 213, 66; (f) W. Fu and Z. Huang, Chemosphere, 2018, 209, 449; (g) X. Wang, S. Jing, Y. Liu, X. Qiu and Y. Tan, $R S C$ Adv., 2017, 7, 13112; (h) X. Wang, S. Jing, Z. Hou, Y. Liu, X. Qiu, Y. Liu and Y. Tan, J. Mater. Sci., 2018, 53, 15009; (i) D. Xue, T. Li, G. Chen, Y. Liu, D. Zhang, Q. Guo, J. Guo, Y. Yang, J. Sun, B. Su, L. Sun and B. Shao, Polymers, 2019, 11, 1125.

7 C. Teodosiu, G. Barjoveanu, B. R. Sluser, S. A. E. Popa and O. Trofin, Int. J. Life Cycle Assess., 2016, 21, 395.

8 (a) K. J. Edgar, C. M. Buchanan, J. S. Debenham, P. A. Rundquist, B. D. Seiler, M. C. Shelton and D. Tindall, Prog. Polym. Sci., 2001, 26, 1605; (b) D. Klemm, B. Heublein, H.-P. Fink and A. Bohn, Angew. Chem., Int. Ed., 2005, 44, 3358; (c) D. W. O'Connell, C. Birkinshaw and T. F. O'Dwyer, Bioresour. Technol., 2008, 99, 6709; (d) L. Testova, K. Nieminen, P. A. Penttilä, R. Serimaa, A. Potthast and H. Sixta, Carbohydr. Polym., 2014, 100, 185; (e) Y. Liu, Y. Nie, X. Lu, X. Zhang, H. He, F. Pan, L. Zhou, X. Liu, X. Ji and S. Zhang, Green Chem., 2019, 21, 3499.

9 K. Nakakubo, H. Hasegawa, M. Ito, K. Yamazaki, M. Miyaguchi, F. B. Biswas, T. Ikai and K. Maeda, J. Hazard. Mater., 2019, 380, 120816.

10 Other examples of biomass-based sorbents: (a) R. P. Dhakal, K. Inoue, K. Ohto and Y. Baba, Chem. Lett., 2006, 35, 1064; (b) 
A. Gupta, V. S. Chauhan and N. Sankararamakrishnan, Water Res., 2009, 43, 3862; (c) Y. Ge, D. Xiao, Z. Li and X. Cui, J. Mater. Chem. A, 2014, 2, 2136; J. Mater. Chem. A, 2015, 3, 7666; (d) Z. Li, D. Xiao, Y. Ge and S. Koehler, ACS Appl. Mater. Interfaces, 2015, 7, 15000; (e) R. Ahmad and I. Hasan, Sep. Sci. Technol., 2016, 51, 381; (f) S. W. Khor, Y. K. Lee, M. R. Bin Abas and K. S. Tay, J. Sol-Gel Sci. Technol., 2017, 82, 834; (g) B. M. Córdova, C. R. Jacinto, H. Alarcón, I. M. Mejía, R. C. López, D. de Oliveira Silva, E. T. G. Cavalheiro, T. Venâncio, J. Z. Dávalos and A. C. Valderrama, Int. J. Biol. Macromol., 2018, 120, 2259; (h) R. G. Huamani-Palomino, C. R. Jacinto, H. Alarcón, I. M. Mejía, R. C. López, D. de Oliveira Silva, E. T. G. Cavalheiro, T. Venâncio, J. Z. Dávalos and A. C. Valderrama, Int. J. Biol. Macromol., 2019, 129, 1056; (i) X. Duan, B. Han, G. Sun and Y. Cui, Chem. Lett., 2019,
48, 1300; (j) B. Li, J.-Z. Guo, J.-L. Liu, L. Fang, J.-Q. Lv and K. Lv, Sci. Total Environ., 2020, 714, 136897.

11 (a) S. J. Joris, K. I. Aspila and C. L. Chakrabarti, Anal. Chem., 1970, 42, 647; (b) F. Takami, K. Ikawa, K. Tokuyama, S. Wakahara and T. Maeda, Chem. Pharm. Bull., 1974, 22, 275.

12 R. Liu, Z. Yang, Z. He, L. Wu, C. Hu, W. Wu and J. Qu, Chem. Eng. J., 2016, 304, 986.

13 (a) R. R. Vandebeek, S. J. Joris, K. I. Aspila and C. L. Chakrabarti, Can. J. Chem., 1970, 48, 2204; (b) R. J. Topping and M. M. Jones, Med. Hypotheses, 1988, 27, 55. 14 T. Kanzian, T. A. Nigst, A. Maier, S. Pichl and H. Mayr, Eur. J. Org. Chem., 2009, 6379.

15 A. Donzelli and P. G. Potvin, Inorg. Chem., 2009, 48, 4171.

16 J. Lv, J. Li, D. Zhang-Negrerie, S. Shang, Q. Gao, Y. Du and K. Zhao, Org. Biomol. Chem., 2013, 11, 1929. 